\title{
A ABORDAGEM DA VARIAÇÃO LINGUÍSTICA NO LIVRO DIDÁTICO DO ENSINO FUNDAMENTAL I: UMA BREVE ANÁLISE
}

\section{THE APPROACH OF LINGUISTIC VARIATION IN THE SCHOOL BOOK OF FUNDAMENTAL EDUCATION I: A}

\section{BRIEF ANALYSIS}

Ires Figueredo de Souza*

\begin{abstract}
Resumo: Este artigo tem como objetivo refletir como os livros didáticos de língua portuguesa do Ensino Fundamental I ( $1^{\circ}$ ano) abordam a variação linguística, levando em consideração, que nesta etapa do conhecimento, os alunos ainda estão sendo alfabetizados. Para entender como se dá o processo de ensino/aprendizagem das variações da língua, foi necessária uma breve análise de algumas atividades específicas de dois materiais didáticos selecionados. Questionamentos como "Existe concepção de 'certo' e 'errado'? Como os livros didáticos trabalham a variação linguística?”, desencadearam este estudo. Sabe-se, que é complexo trabalhar as variedades linguísticas numa etapa de ensino em que os alunos ainda estão aprendendo a ler e escrever. Portanto, este artigo pretende contribuir na construção do conhecimento sobre livros didáticos e, principalmente, levantar questionamentos que sejam significativos para o estudo de questões que tratam sobre variações linguísticas, especialmente, no Ensino Fundamental I.
\end{abstract}

Palavras-chave: Livro didático; Variação Linguística; Criança.

Aвstract: This article aims to reflect how the Portuguese language textbooks of Elementary School I (1st year) address linguistic variation, taking into account that in this stage of knowledge, students are still being literate. To understand how the teaching / learning process of language variations takes place, a brief analysis of some specific activities of two selected teaching materials was necessary. Questions such as "How do textbooks work with linguistic variation? Is there a conception of 'right' and 'wrong'?, triggered this study. It is known that it is complex to work with linguistic varieties in a teaching stage in which students are still learning to read and write.

\footnotetext{
" Mestra em Linguística Aplicada na linha de Ensino do Português, pela Faculdade de Letras da Universidade Federal de Minas Gerais (UFMG). Atualmente, cursa Especialização em Educação e Tecnologias pela Universidade Federal de São Carlos (UFSCar). E-mail: iresfs@hotmail.com.
} 
Therefore, this article aims to contribute to the construction of knowledge about textbooks and, above all, to raise questions that are obtained for the study of issues that deal with linguistic variations, especially in Elementary School I.

KEYwords: Textbook; Linguistic variation; Child.

\section{INTRODUÇÃo}

A aquisição da escrita e da leitura é uma importante etapa do ensino/aprendizagem das crianças. Trata-se do período de reconhecimento e conhecimento das letras, das vogais, dos sons da fala, do processo de leitura. Meireles e Correa (2005, p. 77) apontam que a ortografia possui diversas facetas que devem ser consideradas pela criança, já que as suas regras não são da mesma natureza, e envolvem diferentes habilidades para sua aquisição. Desse modo, os sistemas de escrita e de leitura se dão através do desenvolvimento cognitivo, levando-se em consideração o ambiente social a que a criança está exposta (FERREIRO; TEBEROSKY, 1991, p. 43). Ponderamos, nesse contexto, que é importante não desconsiderar o que a criança já sabe da língua. Ferreiro e Teberosky (1991, p. 24) apontam para o fato de que "a criança que chega à escola tem notável conhecimento de sua língua materna, um saber linguístico que utiliza 'sem saber' (inconscientemente) nos seus atos de comunicação cotidianos”. O conhecimento linguístico da criança sobre sua língua materna contribui para o processo de aquisição de alfabetização, pois facilita sua aprendizagem e se expande à medida que se desenvolve. Segundo Silva (2004, p. 27):

Qualquer indivíduo normal que entre na escola para ser alfabetizado em sua língua materna já é senhor de sua língua, na sua modalidade oral própria a sua comunidade de fala. Admitido esse princípio, qualquer trabalho de ensino da língua materna se constitui em um processo de enriquecimento do potencial linguístico do falante nativo.

Dessa forma, embora as habilidades de escrita e leitura sejam distintas do conhecimento linguístico, esse conhecimento contribui para que a criança compreenda melhor o processo de leitura e escrita, pois já possui um potencial linguístico. Ao considerarmos, então, o "saber inconsciente" da criança, nos questionamos sobre como o livro didático aborda a variação linguística nessa etapa de aprendizagem e aquisição, pois "é um lugar comum insistir em que se deve corrigir a pronúncia dos alunos para evitar dificuldades na aprendizagem da leitura e da escrita" (FERREIRO; TEBEROSKY, 1991, p. 248). À vista disso, é importante analisar os materiais didáticos voltados para alfabetização e pesquisar como eles tratam essa temática sem desconsiderar ou corrigir o que a criança já sabe. O livro, sendo um dos recursos escolares utilizado pelo professor, pode ou não apontar caminhos para esse tipo de abordagem. 
O livro didático é um importante material de apoio pedagógico utilizado pelos docentes. Segundo Costa Val e Marcushi:

O livro didático desempenha, hoje, na escola, uma função proeminente, seja na delimitação da proposta pedagógica a ser trabalhada em sala de aula, seja como material de apoio ao encaminhamento das atividades de ensino-aprendizagem, seja como suporte (único ou suplementar) disponível de textos de leitura para professores e alunos (COSTA VAL; MARCUSHI, 2005, p. 8).

Trata-se, portanto, de um apoio didático que influencia nas abordagens de ensino escolar, sendo, muitas vezes, usado na orientação do planejamento anual de conteúdos curriculares das disciplinas escolares e/ou do professor. Além disso, é um material pedagógico que é atualizado de tempos em tempos e, ultimamente, está de acordo com a Base Nacional Comum Curricular (BNCC). Dessa maneira, o livro didático contribui para implementação da BNCC nas escolas, já que é uma referência obrigatória para os currículos. Assim, dentro desse contexto pedagógico e sendo um material didático proeminente, nos questionamos sobre a abordagem das variações linguísticas nos livros didáticos e como eles trabalham a questão da variação ${ }^{1}$, levando em consideração que o livro do Ensino Fundamental I, nosso foco de estudo, é destinado às crianças que estão em fase de aquisição da leitura e escrita.

Posto isso, o objetivo deste artigo é refletir como o livro didático de língua portuguesa do Ensino Fundamental I ( $1^{\circ}$ ano) aborda a variação linguística. O entendimento e exploração de estudos que tratem da variação linguística na aquisição da leitura e escrita de crianças podem, possivelmente, colaborar para que professores compreendam melhor essa temática e sejam capazes de mediar o ensino pedagógico, juntamente com as contribuições dos materiais didáticos. Para tanto, foram selecionados dois livros de alfabetização (que foram escolhidos de forma aleatória) destinados ao Ensino Fundamental I ( $1^{\circ}$ ano), a saber: Juntos Nessa - Língua Portuguesa - letramento e alfabetização, da autora Daniela Passos, aprovado pelo PNLD 2016 e utilizado pelas escolas até 2018 e o livro Novo Pitanguá - Língua Portuguesa - Ensino Fundamental anos iniciais, da autora Cristiane Buranello, aprovado pelo PNLD de 2019 e que será utilizado pelas escolas até 2022.

\footnotetext{
${ }^{1}$ A variação linguística se constitui como "um fenômeno universal e pressupõe a existência de formas linguísticas alternativas" (MOLLICA, 2004, p. 10). Neste trabalho, interessa-nos investigar, especificamente, a variação diastrática e a variação diatópica. A variação diastrática se refere ao "tipo de variação que ocorre em diferentes grupos sociais" (SOUZA, 2019, p. 35) e a variação diatópica se refere "às distinções que uma mesma língua apresenta em lugares/regiões diferentes do mesmo país ou em outros países” (SOUZA, 2019, p. 34).
} 


\section{AQUiSIÇÃo DA ESCRITA E DA LEITURA}

A aquisição da escrita é um processo que se desenvolve durante todo o período escolar da criança, começando através da leitura de palavras e imagens. De acordo com Ferreiro e Teberosky (1991), as primeiras tentativas de escrita são de dois tipos: traços ondulados contínuos ou uma série de pequenos círculos. Segundo Silva (1994, p. 9), "o trabalho simultâneo com a linguagem oral e escrita implícito nessa nova atividade faz com que a criança utilize a escrita como um lugar privilegiado de reflexão e atuação sobre a linguagem".

Para Abaurre, Fiad e Mayrink-Sabinson (1997), a aquisição da escrita é um momento particular. Trata-se de uma identificação da criança com o código escrito e uma aprendizagem individual. Segundo Cagliari, a criança procura algo para descobrir o sistema escrito:

Uma criança, na sala de alfabetização, encontra-se numa situação semelhante à de um cientista diante de um documento com uma escrita não decifrada. Ambos começam a procurar uma entrada para esse mundo, para descobrir como o sistema de escrita funciona (CAGLIARI, 1998, p. 39).

Nesse caso, é uma nova descoberta, uma nova identificação para a criança, já que, ao mesmo tempo em que ela "armazena e organiza seu conhecimento linguístico através da experiência, ela constrói diferentes hipóteses sobre o funcionamento da língua em seus diferentes componentes" (SILVA; GUIMARÃES, 2013, p. 318).

A aquisição da leitura, por sua vez, exige uma série de estratégias. Segundo Ferreiro e Palacio (1987, p. 16):

A leitura como qualquer atividade humana é uma conduta condizente. As pessoas não respondem simplesmente aos estímulos do meio; encontram ordem e estrutura no mundo de tal maneira que podem aprender a partir de suas experiências, antecipá-las e compreendê-las.

Ferreiro e Teberosky (1999) apontam alguns níveis pelos quais as crianças passam durante o processo de aquisição. A saber:

Nível 1 - Neste nível, escrever é reproduzir os traços típicos da escrita que a criança identifica como forma básica de escrita.

Nível 2 - Para poder ler as coisas diferentes deve haver uma diferença objetiva nas escritas.

Nível 3 - Este nível está caracterizado pela tentativa de dar um valor sonoro a cada uma das letras que compõem uma escrita.

Nível 4 - Passagem da hipótese silábica para alfabética. (FERREIRO; TEBEROSKY, 1999, p. 193-214). 
Perpassadas, então, essas etapas, diz-se que a criança está no nível alfabético. Porém, cada criança é única e a aprendizagem ocorrerá de forma diferenciada para cada uma. Ferrero e Teberosky (1991) salientam que o que a escola pretende ensinar nem sempre coincide com o que a criança consegue aprender. Sendo assim, acreditamos que, no sistema de aquisição da escrita e da leitura, é necessário que o professor facilite esse processo e utilize de práticas de letramento para ajudar as crianças, despertando nelas o gosto de pela leitura e escrita. Por fim, pensamos, como Cagliari (1998, p. 370), que "o método de alfabetização deve levar em conta o processo de aprendizagem deixando um espaço para que o aluno exponha suas ideias a respeito do que aprende".

\section{O ENSINO DA VARIAÇÃO LINGUÍSTICA}

Segundo a Sociolinguística, a língua é dotada de "heterogeneidade sistemática" (WEINREICH; LABOV; HERZOG, 2006, p. 101). Para este trabalho, adotamos, como pressuposto linguístico, a concepção da língua como um fenômeno heterogêneo. Segundo Castilho (2000, p. 12), a língua é "um fenômeno funcionalmente heterogêneo, representável por meio de regras variáveis socialmente motivadas”. Dessa forma, a língua não é estática, ela muda, altera, renova, enfim, ela é viva e possui um caráter social, sendo constituída por regras variáveis. Segundo Bagno (2009, p. 27) "não existe nenhuma língua no mundo que seja uniforme e homogênea”. Portanto, não sendo restrita a um único jeito específico e não sendo estática, a língua muda com o tempo, de acordo com o lugar, com o contexto ou mesmo com situações de grupos sociais distintos. O fruto de toda essa diversidade é a grande variedade nos modos de falar a que a "Sociolinguística reserva o nome de variedades linguísticas" (ALKMIM, 2001, p. 32).

O ensino da variação linguística na educação infantil é algo extremamente importante, mas também delicado, pois é a etapa da educação em que os alunos estão desenvolvendo o conhecimento linguístico. Desse modo, situações como "corrigir" a criança para que ela aprenda a escrever "certo" devem ser pontuadas, pois podem desencadear insegurança no aluno em processo de aprendizagem. Ademais, é importante ressaltar que, na etapa pré-escolar, é preciso ser cuidadoso com essas "correções", atentando-se para a questão do tratamento das variações linguísticas e sabendo que os alunos estão em fase de aquisição de leitura e escrita.

No documental oficial de currículos e conteúdos da Educação Infantil, denominado de Referencial Curricular Nacional para Educação Infantil, destinado a alunos de 0 a 6 anos, percebe-se que existe uma ponderação acerca da linguagem oral e, consequentemente, de suas variações. O volume 3 do Referencial Curricular da Educação Infantil evidencia uma preocupação educacional voltada para uma concepção de língua social, sendo, portanto, importante o ensino da variação linguística nessa etapa educacional, como aborda o documento: 
A linguagem oral possibilita comunicar ideias, pensamentos e intenções de diversas naturezas, influenciar o outro e estabelecer relações interpessoais. Seu aprendizado acontece dentro de um contexto. As palavras só têm sentido em enunciados e textos que significam e são significados por situações. A linguagem não é apenas vocabulário, lista de palavras ou sentenças. É por meio do diálogo que a comunicação acontece. São os sujeitos em interações singulares que atribuem sentidos únicos às falas. A linguagem não é homogênea: há variedades de falas, diferenças nos graus de formalidade e nas convenções do que se pode e deve falar em determinadas situações comunicativas. Quanto mais as crianças puderem falar em situações diferentes, como contar o que lhes aconteceu em casa, contar histórias, dar um recado, explicar um jogo ou pedir uma informação, mais poderão desenvolver suas capacidades comunicativas de maneira significativa. (BRASIL, 2016, p. 121, grifo nosso).

Constata-se, por meio do referencial, que o estudo e ensino da variação, na etapa de Educação Infantil, é algo relevante e não se pode privar a criança desse conhecimento. Ao contrário, o professor pode buscar alternativas que estejam de acordo com as realidades linguísticas dos alunos, bem como materiais didáticos que contribuam nesse sentido. Para essa aplicabilidade, por exemplo, o professor pode realizar simulações de situações informais para que as crianças conversem, pode contar histórias que utilizem de variedades coloquiais para que as crianças entendam e percebam as diferenças entre as variedades linguísticas. É extremamente importante que as crianças estejam expostas a esse tipo de atividades, visto que em casa e outras situações sociais, elas utilizam de diversas variedades linguísticas para se comunicar, por isso é necessário que a escola também trate sobre essa temática.

\section{A ABordagem da VARIAÇão LINGUística NOS LIVROS DidÁticos: UMA BREVE ANÁLISE}

O ensino da leitura e escrita na alfabetização, bem como o ensino da Língua Portuguesa, configura-se como algo delicado e o método de instrução, por vezes, é questionado por muitos pesquisadores, tanto no âmbito dos materiais didáticos, quanto nas práticas pedagógicas. Tal situação ocorre pelo fato de se ter a norma padrão ${ }^{2}$ como a "ideal", desconsiderando, em alguns casos, as variedades linguísticas. Nesse caso, deve-se levar em consideração que "a pluralidade cultural e a rejeição aos preconceitos linguísticos são valores que precisam ser cultivados a partir da educação infantil e do ensino fundamental” (BORTONI-RICARDO, 2004, p. 35). Segundo Bagno (1999, p. 9), "o preconceito linguístico está ligado, em boa medida, à confusão que foi criada, no curso da história, entre língua e gramática normativa”. Tal confusão se dá pelo fato de as pessoas compararem os modos de falar do cotidiano com o modelo elaborado pelas gramáticas. Com isso, o preconceito linguístico afeta a educação escolar à medida que

2"Norma-padrão é a norma prescrita pelas chamadas gramáticas normativas" (MONTEIRO,2014, p. 14). 
privilegia uma variedade em detrimento de outra, contribuindo para um ambiente hostil e que não respeita as variedades da língua. Com uma metodologia de ensino variacionista, esse quadro de preconceito linguístico pode ser desconstruído, pois os alunos terão entendimento sobre as diversas variedades e saberão usar cada uma de acordo com a situação e contexto social.

Sob esse viés, ressaltamos a importância de se trabalhar a variação linguística desde a Educação Infantil, e a relevância dessa abordagem nos materiais didáticos. A partir da análise, verificamos situações distintas nos livros selecionados. O primeiro livro foi o Juntos Nessa.

Figura 1: Capa do livro Juntos Nessa

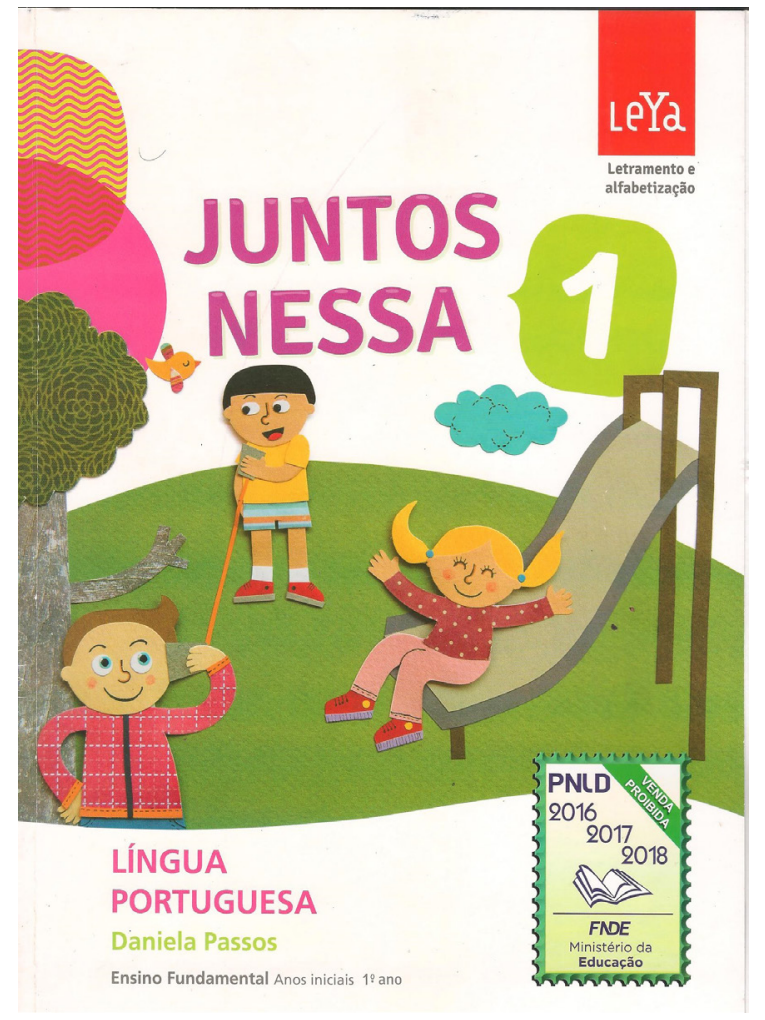

Fonte: Passos (2014).

Em nossa breve investigação, percebemos que o livro Juntos Nessa, como um todo, apresenta atividades voltadas para aquisição da escrita dentro da perspectiva da norma padrão da língua. Em algumas seções, tem atividades voltadas para a consciência fonológica dos alunos, além de apresentar várias propostas de produção escrita, histórias e situações da língua falada. Vemos que a preocupação da autora do material em trabalhar com questões de oralidade é algo positivo, levando em consideração que as crianças estão expostas a diversos meios de comunicação e situações cotidianas que exigem o diálogo/fala. O livro é bem ilustrado e bastante explicativo (no caso do manual do professor), o que facilita o entendimento de determinados conteúdos. Algumas atividades fazem retomadas de outros exercícios do 
próprio livro, deixando clara a página para consulta, e contribuindo para que o aluno possa compreender melhor e/ou fazer uma comparação. Em suma, é um material bem elaborado, com muitas atividades complementares e textos voltados às situações sociais, como o bullying ${ }^{3}$, por exemplo. Em contrapartida, em uma determinada atividade de oralidade, nos deparamos com uma situação diferenciada.

Figura 2: Produção oral de brincadeira

PRODUÇÃO ORAL

\section{CONVERSA TELEFÔNICA}

VAMOS BRINCAR DE CONVERSA TELEFÔNICA? O(A) PROFESSOR(A) VAI ORGANIZAR A TURMA EM DUPLAS PARA QUE TODOS POSSAM "FALAR AO TELEFONE" USANDO OS TELEFONES DE FIO CONFECCIONADOS PELA TURMA.

\section{PLANEJEM A FALA}

- pensem no assunto sobre o qual conversarão: pode SER SOBRE A VISITA DE UM COLEGA A SUA CASA, UM PASSEIO, UMA EXPLICAÇĀO DE ALGUMA TAREFA OU SOBRE UM RECADO $A O(A)$ PROFESSOR(A).

- DECIDAM QUEM VAI "LIGAR" PARA QUEM.

AO FALAR, LEMBREM-SE DE:

- SE APRESENTAR, JÁ QUE a OUTRA PESSOA NÃo Vê QUEM ESTÁ AO TELEFONE, APENAS ESCUTA;

- inICIAR a conVersa com um CUMPRIMENTO, OU SEja, DIga "ALÔ", "OI", "OLÁ", "BOM DIA" OU "BOA TARDE" E PERGUNTE COMO A PESSOA ESTÁ;

- falar de maneira clara;

- esperar o amigo terminar de falar para só então COMEÇAR;

- NÃO EXAGERAR NA UTILIZAÇÃo de ALGUMAS EXPRESSÕES PRÓPRIAS DA FALA, COMO NÉ E TIPO ASSIM, ENTRE OUTRAS;

- DESPEDIR-SE AO TERMINAR A CONVERSA.

Fonte: Passos (2014, p. 66).

\footnotetext{
${ }^{3} \mathrm{O}$ bullying pode ser definido como "um conjunto de atitudes agressivas, intencionais e repetidas que ocorrem sem motivação evidente, adotado por um ou mais alunos contra outros(s), causando dor, angústia e sofrimento. Insultos, intimidações, apelidos cruéis, gozações que magoam profundamente, acusações injustas, atuações de grupos que hostilizam, ridicularizam e infernizam a vida de outros alunos, levando-o a exclusão, além de danos físicos, morais e materiais, são algumas manifestações do comportamento bullying" (FANTE, 2005, p. 28-29).
} 
Nesta parte, denominada de "Produção Oral", vemos uma proposta de brincadeira oral de simulação de conversa ao telefone, que as crianças devem realizar com a mediação do professor. Em seguida, a atividade mostra alguns planejamentos que devem ser seguidos pelos alunos. No penúltimo planejamento, há o seguinte comando: "Não exagerar na utilização de algumas expressões próprias da fala, como né e tipo assim, entre outras". Tal comando pareceu restringir, de certo modo, o falar das crianças, uma vez que se refere às expressões da fala. Percebemos que se trata de algo negativo em um material didático, pois ignora as variantes diastráticas. Acreditamos que, nessa atividade específica, é necessária a intervenção e explicação do professor, para que as crianças não se sintam estigmatizadas ou inibidas a usar suas variantes linguísticas. Na página seguinte, após essa atividade, o livro dá alguns exemplos de falas que poderiam ser utilizadas pelos alunos na brincadeira do telefone, mas pensamos que não precisaria da prescrição anterior, já que o exemplo foi bem colocado para explicar.

Por outro lado, em outras partes do mesmo livro, existem atividades de produção oral que não limitam a fala do aluno. Como exemplo, a atividade da Figura 3.

Figura 3: Produção oral de história

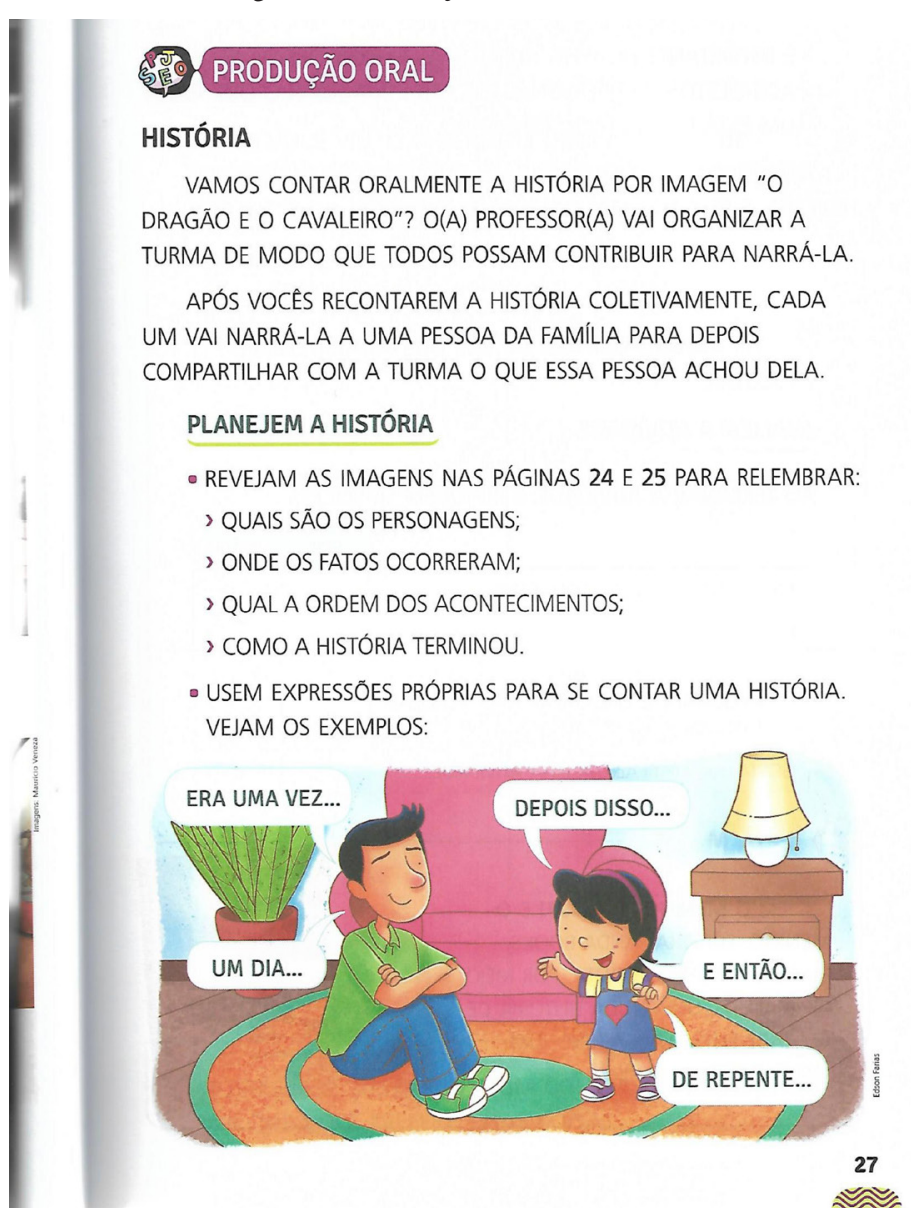

Fonte: Passos (2014, p. 27). 
A Figura 3 consiste em uma atividade de produção oral de história. Embora a atividade já direcione os alunos com alguns exemplos de expressões utilizadas para contar histórias, trata-se de uma atividade positiva. Não há nenhum indício de limitação ou restrição da fala das crianças, ao contrário, o aluno terá liberdade para contar a história com suas próprias palavras. Entretanto, não foi abordado o ensino de variação linguística.

O outro livro analisado foi o livro Novo Pitanguá.

Figura 4: Capa do livro Novo Pitanguá

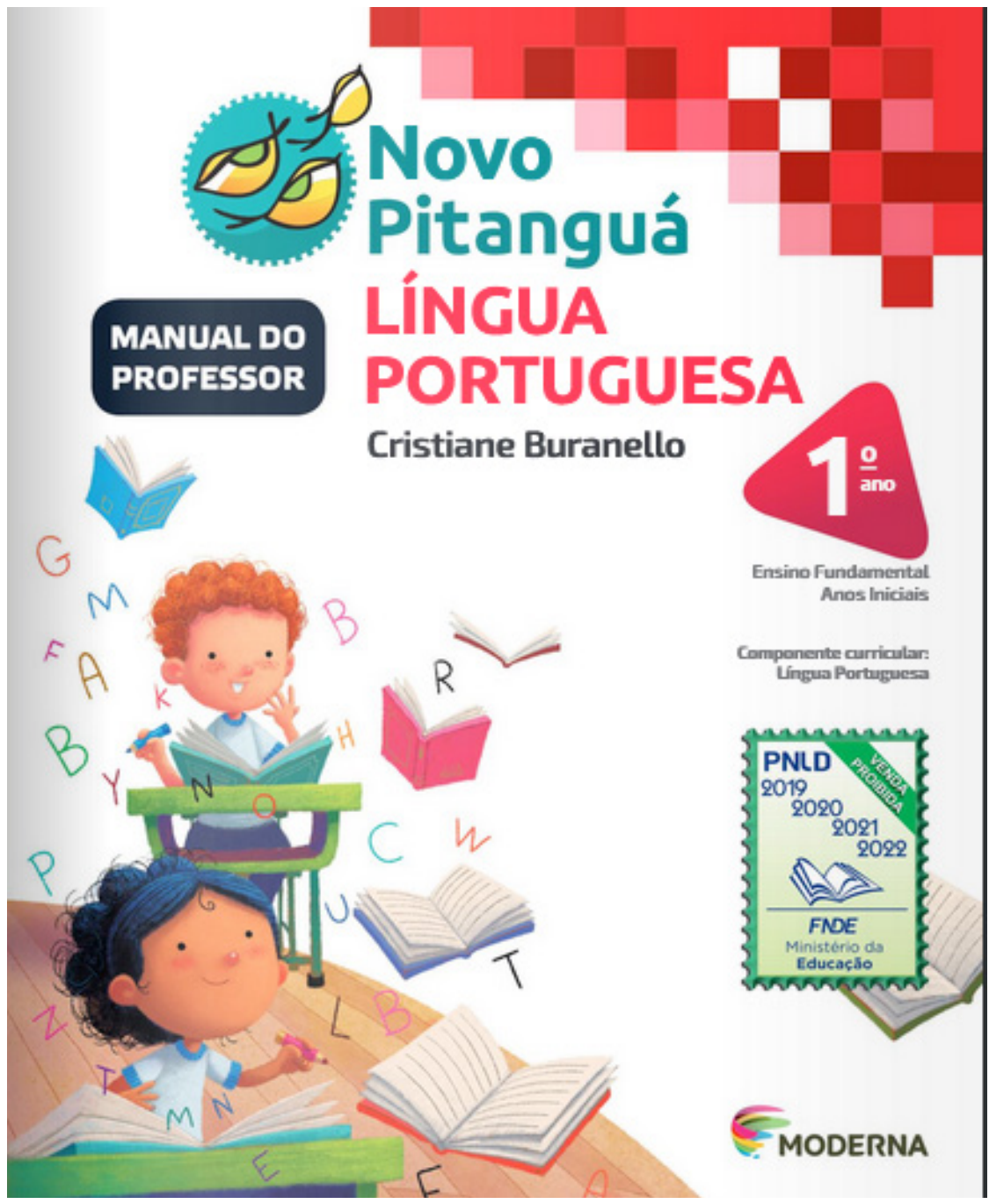

Fonte: Buranello (2017).

O livro Novo Pitanguá é composto de imagens, histórias, muitas atividades de produção textual (oral e escrita), além de diversas questões que contribuem para a consciência fonológica. Assim como no livro anterior, a escrita e as atividades, como um todo, são voltadas para a 
norma padrão. Entretanto, em nenhum momento, houve alguma atividade ou questão que pudesse restringir ou inibir a fala ou o uso da modalidade linguística usada pelo aluno. O livro focaliza muitas questões de fonologia e interpretação de texto, o que, por nós, foi visto como algo positivo, já que possibilita a consciência fonológica e entendimento do aluno acerca dos textos lidos. Além disso, o livro apresenta um grande repertório de atividades voltadas para a oralidade. Como exemplo, temos a figura a seguir.

Figura 5: Exposição oral

\section{PRODUÇÃO ORAL}

\section{EXPOSIÇÃO ORAL}

VOCÉ E OS COLEGAS ORGANIZARAM O CANTINHO DA LEITURA E CONVIDARAM OS FAMILIARES PARA CONHECEE-LO.

AGORA, EXPLIQUEM PARA ELES UM POUCO SOBRE O QUE Ė ESSE LUGAR E COMO VOCÊS O ORGANIZARAM. VEJA ALGUMAS SUGESTÖES DO QUE VOCÉS PODEM EXPLICAR AOS FAMILIARES.

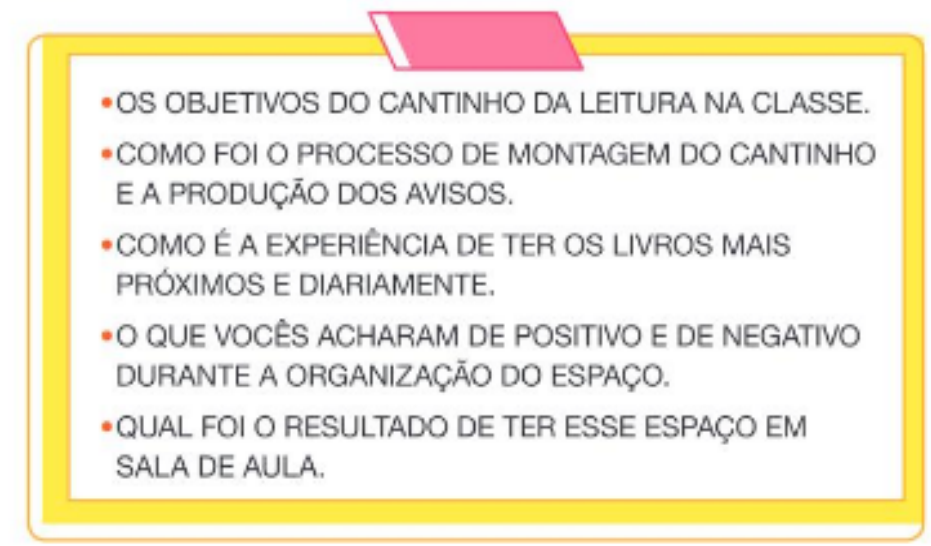

PARA AJUDÁ-LOS NA HORA DA EXPLICAÇĀO, SIGAM ESTAS DICAS.
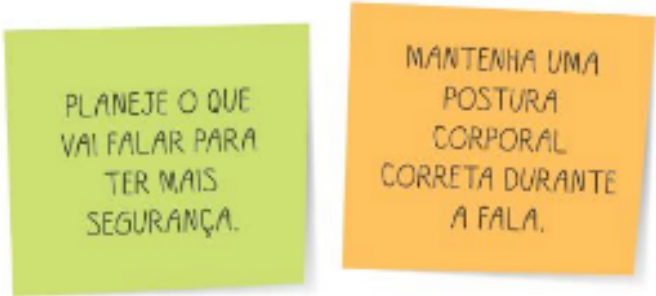

$$
\begin{aligned}
& \text { USE UM TOM OE VOZ } \\
& \text { QUE DESPERTE O } \\
& \text { INTERESSE DAS } \\
& \text { PESSOAS PELA } \\
& \text { EXPLICAÇAOA. }
\end{aligned}
$$

PARA AVALIAR AS APRESENTAÇŌES E O DESENVOLVIMENTO DA EXPOSICৃĀO, REÚNAM-SE EM UMA PRÓXIMA AULA, DIGAM DO QUE GOSTARAM E CONTEM SE SENTIRAM ALGUMA DIFICULDADE.

Fonte: Buranello (2017, p. 90). 
Nesta atividade, os alunos devem realizar uma apresentação oral sobre o cantinho da leitura organizado pela classe. Dentro das orientações de produção, em nenhum item foi verificado algum comando que pudesse delimitar ou conter a fala dos alunos. Tal questão foi verificada em toda a extensão do livro, não havendo, portanto, em nenhuma atividade de oralidade, alguma restrição de fala. Nesse ponto, analisamos como positivo esse posicionamento do material didático. Em toda extensão do livro, é importante que o professor dialogue com os alunos e explore a questão das variações, principalmente se foi usada alguma outra variedade e, também, abordar o preconceito linguístico. Dessa forma, os alunos terão a consciência linguística de respeito e um melhor entendimento sobre as diversas maneiras de falar. Por fim, assim como a obra anterior, este livro também não aborda diretamente o ensino da variação linguística. Em ambos os exemplares, a temática da variação deve ser ensinada e mediada pelo professor.

\section{CoNSIDERAÇõES FINAIS}

Neste artigo, procuramos refletir sobre como o livro didático de língua portuguesa do Ensino Fundamental I aborda a variação linguística. Para isso, realizou-se uma breve análise de dois livros, destinados ao $1^{\circ}$ ano do Ensino Fundamental I. Partimos do pressuposto de que a abordagem da variação linguística nos anos iniciais do Ensino Fundamental é algo importante, pois os alunos estão em fase de aquisição da escrita, bem como da leitura.

É importante destacar que a escola tem a função de promover condições para que a criança desenvolva a competência linguística para situações comunicativas diversas. Para isso, é necessário ter atenção para que a norma padrão não seja a única estudada e privilegiada. Entendemos que a criança já domina a língua e faz uso dela através das comunicações sociais. Por meio da aquisição da escrita, o conhecimento linguístico se expande e, assim, o aluno tem acesso ao código alfabético, tendo, portanto, a possibilidade de se conscientizar melhor sobre sua fala, já que

Uma das principais tarefas do professor de língua é conscientizar seu aluno de que a língua é como um grande guarda-roupa onde é possível encontrar todo tipo de vestimenta. Ninguém vai só de maiô fazer compras num shopping-center, nem vai entrar na praia, num dia de sol quente, usando terno de lã, chapéu de feltro e luvas (BAGNO, 1999, p. 129).

Por esse motivo, o estudo das variações linguísticas, já na infância, contribui para que o aluno reflita sobre o que está aprendendo e conheça melhor sobre a língua.

É perceptível que os livros didáticos utilizam a norma padrão. Salientamos, nesse sentido, que não é errado os livros ensinarem sobre a norma padrão, ao contrário, é importante 
seu ensino e ele será, muitas vezes, requisitado na sociedade. A questão aqui colocada é que não seja a única modalidade linguística em questão. Os livros que analisamos, por exemplo, demonstram uma preocupação em abordar atividades orais e de produção escrita, o que é considerável e importante, tendo em vista que a língua faz parte da realidade dos alunos. Por outro lado, não encontramos abordagem e/ou ensino sobre a variação diastrópica ou variação diastrática.

Sobre o ensino da variação linguística nos livros analisados, a mediação do professor é necessária em algumas atividades específicas, desse modo, o professor pode explicar para os alunos alguns usos que o livro inibe. Ressaltamos, ainda, que apesar de ter atividades que possam restringir a linguagem do aluno, os dois livros analisados, em nenhum momento, usaram da expressão de "certo" ou "errado" para designar algum termo, fala, escrita ou uso da língua. Isso é um ponto favorável, ainda que não tenha abordado sobre a variação linguística.

Por fim, concluímos que é relevante que haja mais pesquisas e investigações sobre os materiais didáticos e variação linguística a fim de criar mecanismos pedagógicos que auxiliem melhor na reflexão sobre a língua. Além disso, esperamos que este estudo possa instigar reflexões sobre investigações que tratam da elaboração e produção de livros didáticos e destinados ao Ensino Fundamental I.

\section{REFERÊNCIAS}

ABAURRE, Maria Bernadete Marques; FIAD, Raquel Salek; MAYRINK-SABINSON, Maria Laura Trindade. Cenas de aquisição da escrita: o sujeito e o trabalho com o texto. Campinas, SP: Mercado de Letras, Associação de Leitura do Brasil, 1997.

ALKMIM, Tânia Maria. Sociolinguística. In: MUSSALIM, Fernanda; BENTES, Anna Christina. Introdução à linguística: domínios e fronteiras. 5. ed. São Paulo: Cortez, 2001.

BAGNO, Marcos. Preconceito linguístico: o que é, como se faz. 50. ed. São Paulo: Edições Loyola, 2009.

BATISTA, Antônio Augusto Gomes. Um objeto variável e instável: textos, impressos e livros didáticos. In: ABREU, Márcia (Org.). Leitura, história e história da leitura. Campinas: Mercado de Letras; Associação de Leitura do Brasil; São Paulo: Fapesp, 1999.

BORTONI-RICARDO, Stella Maris. Educação em língua materna: a sociolinguística na sala de aula. São Paulo: Parábola, 2004.

BRASIL. Ministério da Educação e do Desporto. Secretaria de Educação Fundamental. Referencial curricular nacional para a educação infantil. Brasília, MEC/ SEF, 1998. Disponível em: http://portal.mec.gov.br/seb/arquivos/pdf/volume3.pdf. Acesso em: 20 jun. 2020.

BURANELLO, Cristiane. Novo Pitanguá: língua portuguesa - manual do professor. 1. ed. São Paulo: Moderna, 2017. 
CAGLIARI, Luiz Carlos. A respeito de alguns fatos do ensino e da aprendizagem da leitura e da escrita pelas crianças na alfabetização. In: ROJO, Roxane Helena (Org.). Alfabetização e letramento: perspectivas linguísticas. São Paulo: Mercado das Letras, 1998. p. 35-49.

CASTILHO, Ataliba Teixeira de. A língua falada no ensino de português. São Paulo: Contexto, 2000.

COSTA VAL, Maria da Graça; MARCUSCHI, Beth. Apresentação. In: COSTA VAL, Maria da Graça; MARCUSCHI, Beth. (Org.). Livros didáticos de língua portuguesa: letramento e cidadania. Belo Horizonte: Ceale/FAE-UFMG: Autêntica, 2005.

FANTE, Cléo. Brincadeiras Perversas. Disponível em: http://www.espiritualidades.com.br/ Artigos/F_autores/FANTE_Cleo_tit_Brincadeiras_perversas_bullying.htm. Acesso em: 9 out. 2020.

FERREIRO, Emília; PALACIO, Margarita Gomes. Os Processos de Leitura e Escrita. 3. ed. Porto Alegre: Artes Médicas, 1987.

FERREIRO, Emilia; TEBEROSKY, Ana. Psicogênese da língua escrita. 4. ed. Porto Alegre: Artes Médicas, 1991.

FERREIRO, Emilia; TEBEROSKY, Ana; CORSO, Mario; LICHTENSTEIN, Myriam Diana; DI MARCO, Liana. Psicogênese da língua escrita. Porto Alegre: Artes Medicas, 1999.

MEIRELES, Elisabet de Sousa; CORREA, Jane. Regras contextuais e morfossintáticas na aquisição da ortografia da língua portuguesa por crianças. Psicologia: Teoria e Pesquisa. Brasília, v. 21, n.1, 2005. Disponível em: http://www.scielo.br/pdf/ptp/v21n1/a11v21n1.pdf. Acesso em: 27 nov. 2017.

MOLLICA, Maria Cecília. Linguística e sociolinguística. In: MOLLICA, Maria Cecília; CIPRIANO, Maria Luiza Braga. Introdução à sociolinguística: tratamento da variação. 2. ed. São Paulo: Contexto, 2004.

MONTEIRO, Davi Miranda. Variação e mudança na norma-padrão do português brasileiro: (des)caminhos da normalização. 2014. Monografia (Especialização em Revisão de Texto) Centro Universitário de Brasília, Brasília, 2014.

PASSOS, Daniela Oliveira. Juntos Nessa: ensino fundamental, anos iniciais-língua portuguesa. $1^{\circ}$ ano. 1. ed. - São Paulo: Leya, 2014.

SILVA, Ademar da. Alfabetização: a escrita espontânea. 2. ed. São Paulo: Contexto, 1994.

SILVA, Rosa Virgínia Mattos e. 0 português são dois: novas fronteiras, velhos problemas. São Paulo: Parábola, 2004.

SILVA, Thais Cristófaro; GUIMARÃES, Daniela Oliveira. A aquisição da linguagem falada e escrita: o papel da consciência linguística. Letras de Hoje, Porto Alegre, v. 48, n. 3, p. 316-323, jul./set. 2013. Disponível em: http://revistaseletronicas.pucrs.br/ojs/index.php/fale/article/ viewFile/12608/9911. Acesso em: 27 nov. 2017. 
SOUZA, Ires Figueredo de. Variação linguística: o enfoque dos livros didáticos de língua portuguesa na educação de jovens e adultos. 2019. 107 f. Dissertação (Mestrado) - Programa de Pós-Graduação em Estudos Linguísticos, Universidade Federal de Minas Gerais, Belo Horizonte, 2019.

VOTRE, Sebastião Josué. Relevância da variável escolaridade. In: MOLLICA, Maria Cecília; BRAGA, Maria Luiza. (Org.). Introdução à Sociolinguística: o tratamento da variação. São Paulo: Contexto, 2003. Cap. 6, p. 51-58.

WEINREICH, Uriel; LABOV, William; HERZOG, Marvin; BAGNO, Marcos. Fundamentos empíricos para uma teoria da mudança linguística. São Paulo: Parábola, 2006.

Recebido para publicação em: 30 jul. 2020. Aceito para publicação em: 10 out. 2020. 